\title{
Exchange across the shelf break at high southern latitudes
}

\author{
J. M. Klinck and M. S. Dinniman \\ Center for Coastal Physical Oceanography, Old Dominion University, Norfolk, Virginia, USA
}

Received: 22 December 2009 - Published in Ocean Sci. Discuss.: 26 January 2010

Revised: 6 May 2010 - Accepted: 14 May 2010 - Published: 28 May 2010

\begin{abstract}
Exchange of water across the Antarctic shelf break has considerable scientific and societal importance due to its effects on circulation and biology of the region, conversion of water masses as part of the global overturning circulation and basal melt of glacial ice and the consequent effect on sea level rise. The focus in this paper is the onshore transport of warm, oceanic Circumpolar Deep Water (CDW); export of dense water from these shelves is equally important, but has been the focus of other recent papers and will not be considered here. A variety of physical mechanisms are described which could play a role in this onshore flux. The relative importance of some processes are evaluated by simple calculations. A numerical model for the Ross Sea continental shelf is used as an example of a more comprehensive evaluation of the details of cross-shelf break exchange. In order for an ocean circulation model to simulate these processes at high southern latitudes, it needs to have high spatial resolution, realistic geometry and bathymetry. Grid spacing smaller than the first baroclinic radius of deformation (a few $\mathrm{km}$ ) is required to adequately represent the circulation. Because of flow-topography interactions, bathymetry needs to be represented at these same small scales. Atmospheric conditions used to force these circulation models also need to be known at a similar small spatial resolution (a few $\mathrm{km}$ ) in order to represent orographically controlled winds (coastal jets) and katabatic winds. Significantly, time variability of surface winds strongly influences the structure of the mixed layer. Daily, if not more frequent, surface fluxes must be imposed for a realistic surface mixed layer. Sea ice and ice shelves are important components of the coastal circulation.
\end{abstract}

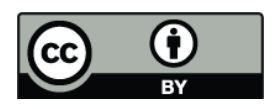

Correspondence to: J. M. Klinck (klinck@ccpo.odu.edu)
Ice isolates the ocean from exchange with the atmosphere, especially in the winter. Melting and freezing of both sea ice and glacial ice influence salinity and thereby the character of shelf water. These water mass conversions are known to have an important effect on export of dense water from many Antarctic coastal areas. An artificial dye, as well as temperature, is used to diagnose the flux of CDW onto the shelf. Model results for the Ross Sea show a vigorous onshore flux of oceanic water across the shelf break both at depth and at the surface as well as creation of dense water (High Salinity Shelf Water) created by coastal polynyas in the western Ross Sea.

\section{Introduction}

The exchange between the deep ocean and continental shelves is typically thought to be important for the processes over the shallower shelf. Cross-shelf exchange brings in nutrients from the ocean, which fuels biological production, as well as salt which balances the effect of river discharge and excess precipitation.

At high southern latitudes around the continent of Antarctica, continental shelves also exchange water with the open ocean. However, the geometry, processes, and even the direction of water exchange can be very different from those on non-polar continental shelves. Antarctic shelves are active participants in the Global Overturning Circulation; some Antarctic shelves (e.g., the Weddell and Ross Seas) are places where dense water is formed. Deep water surfaces just off the shelf break in many areas (e.g., west side of the Antarctic Peninsula) and is converted into either surface or dense water (Rintoul et al., 2001). 
The Antarctic Circumpolar Current (ACC), the largest current on Earth by various measures, flows along the Antarctic shelf break in several areas. This fast, baroclinic current is associated with several processes that affect exchange. In particular, the vertical shear of the ACC is supported by sloping density surfaces that rise to the south (the thermal wind balance). These sloping surfaces provide a path for deep water to rise adiabatically by as much as $3 \mathrm{~km}$ as it moves southward across the ACC. This vertical excursion allows surfacing of Circumpolar Deep Water (CDW) at the continental shelf break (or the base of the surface mixed layer).

Finally, ice plays an important role in the dynamical processes of these shelves. The most obvious is the annual growth and retreat of sea ice which changes the properties of water near the surface and can produce dense water on the shelf through the release of salt during the freezing process. In addition, sea ice insulates the ocean from the atmosphere during the harsh winter, reducing the influence of the extreme cold and the blustery winds.

Less obvious is the effect of the massive ice shelves which are produced by snowfall over Antarctica and which slide remorselessly off the continent into the ocean. These floating ice shelves cover nearly $40 \%$ of the Antarctic continental shelf and thus isolate much of the shelf water from direct atmospheric forcing. Heat exchange between the not-quite freezing ocean water and the base of the ice shelf melts the glacial ice and cools (and freshens) the water. This basal melt of the glaciers produces a buoyancy driven circulation, sometimes called the "ice pump" (Lewis and Perkins, 1986), which influences water properties on the shelf and, thus, circulation and shelf break exchange.

The focus of this paper is on mechanisms responsible for onshore flux of CDW which has important effects on a number of properties and processes on Antarctic continental shelves. An equally important offshore flux of dense water, which is created on Antarctic shelves, is not discussed in detail as it is the focus of extensive analysis presented elsewhere (Ivanov et al., 2004; Legg et al., 2009; Gordon et al., 2009).

The next section provides an overview of Antarctic continental shelves. It is followed by descriptions of several processes that could move CDW onto the shelf. Section 4 provides some details of a model applied to the Ross Sea which illustrates the details of ocean-shelf exchange. Section 5 gives some results from Ross Sea simulations compared to climatology and some estimates of cross-shelf exchange. Section 6 comments on the effects of bottom topography and polynyas on exchange processes. Speculation is included on the effects of anticipated climate changes. The last section offers conclusions.

\section{Overview of Antarctic shelves}

Antarctic continental shelves are different in a number of ways from those at lower latitudes. First, they are relatively deep (about 400 to $600 \mathrm{~m}$ on average and more than $1500 \mathrm{~m}$ in places), due mainly to the isostatic loading of the land by the weighty ice sheet. Bottom topography over these shelves is very rugged due to the scouring of the bottom by the ice sheets over various times in the past. Deep troughs have been cut by long vanished ice sheets (ten Brink and Cooper, 1992).

In most places on Antarctic shelves, the stratification is weak, due mainly to the lack of precipitation and coastal runoff, producing relatively uniform salinity; and strong surface cooling, producing uniform, cold temperatures. The resulting internal radius of deformation over most of the Antarctic continental shelf is about 4 to $5 \mathrm{~km}$ (Hofmann and Klinck, 1998). A small internal radius means that geostrophic flow can follow paths with radii of curvature of a few internal radii $(\sim 10 \mathrm{~km})$ and that mesoscale eddies will have diameters of 10 to $20 \mathrm{~km}$.

Tides provide high frequency flow variability to most parts of the ocean. There are regions in the Southern Ocean (e.g., west of the Antarctic Peninsula) where tidal energy is low while other places (e.g., over the Ross Sea) where tides are energetic (Padman et al., 2002; Erofeeva et al., 2005). There are two general ways that tides affect exchange: enhancing basal melt under ice shelves (Makinson, 2002) and modifying the location of shelf break fronts (Padman et al., 2009). Both of these influences of tides are important in certain areas and both are being actively investigated. Basal melt of ice shelves is thought to be a weak driver of cross shelf exchange (details below) so is not discussed further. The effect of tides on the shelf break front seems to influence the release of dense water from continental shelves which we have chosen not to pursue in this paper.

Atmospheric conditions at high southern latitudes, being cold, dry, and windy, produce vigorous exchange with the ocean. Solar insolation has a strong seasonal dependence varying from moderate strength to non-existent. These surface fluxes give rise to relatively deep surface mixed layers over the shelf (about $100 \mathrm{~m}$ ), which can extend to the bottom for sufficiently strong cooling (and ice formation) in the winter.

The freezing of the ocean surface to produce sea ice gives rise to a kind of salt pump in which brine produced during freezing sinks away from the surface ocean increasing the salinity of the subsurface waters. Melting of sea ice in the summer reduces the surface salinity producing an increased stratification and a persistent pycnocline at a depth of about $200 \mathrm{~m}$.

If winds push away newly formed ice, then freezing is nearly continuous forming a polynya. In these cases, increasingly dense water is formed which results in very deep mixing - to the bottom, in most cases. 


\section{Possible dynamics for CDW intrusions}

CDW has a distinctive warm and saline character and occurs along almost all of the Antarctic continental shelf break; although with different temperatures at different locations. The exchange of CDW onto the shelf has the potential to moderate sea ice cover, provides macro- and possibly micronutrients for primary production, and provides a relatively warm, subsurface habitat for some animals, such as krill (Hofmann and Hüsrevoğlu, 2003).

In addition, this warmer water intruding onto the shelf is a source of heat which moderates sea ice cover and melts the bottom of floating ice shelves which could increase the rate at which glacial ice sheets slide off the continent into the ocean which would lead to a rise in global sea level. For all of these reasons, the exchange of this water mass between the ocean and shelf is important for both physical and biological processes on Antarctic shelves.

Intrusions of warm oceanic CDW across the shelf break can be driven by a variety of physical processes. The subsections below describe possible mechanisms.

\subsection{Bottom Ekman layer}

The flow along the shelf break of the Bellingshausen Sea $\left(105^{\circ} \mathrm{W}\right.$ to $\left.70^{\circ} \mathrm{W}\right)$ is mostly eastward. The bottom Ekman transport in the Southern Hemisphere is to the right of the overlying flow; so, along this part of the Antarctic Coast, the bottom frictional layer will transport water onshore. A similar onshore frictional transport would occur along the west side of the Antarctic Peninsula (WAP).

Farther to the west, the flow along the shelf break of the Amundsen and Ross Seas is towards the west due to the ACC being offshore and the westward flow being the southern part of the Ross Sea Gyre (Gouretski, 1999). Along this coast, the bottom frictional transport is offshore.

The total onshore transport per unit width $(T)$ is controlled by the speed of the overlying flow $(U)$ and the bottom Ekman thickness $(D)$, so that $T=.5 U D$ (Cushman-Roisin, 1994, p. 66). The estimated onshore transport is about $0.5 \mathrm{~m}^{2} \mathrm{~s}^{-1}$ for a $10 \mathrm{~m}$ Ekman depth and $0.1 \mathrm{~m} \mathrm{~s}^{-1}$ overlying flow.

This onshore transport would not have a strong effect on the typical shelf as indicated by an estimated flushing time. For a shelf that is $150 \mathrm{~km}$ wide and $500 \mathrm{~m}$ deep, the estimated flushing time is about $5 \mathrm{yr}\left[(150 \mathrm{~km})(500 \mathrm{~m}) / 0.5 \mathrm{~m}^{2} \mathrm{~s}^{-1}\right]$. However, if the frictional layer brings in pure $\mathrm{CDW}\left(1.8^{\circ} \mathrm{C}\right)$, then it would supply about $48 \mathrm{Wm}^{-2}$ of heat over the entire width of the shelf, assuming that there is no heat loss as the water crosses the shelf. Exchanging cooler CDW (say, -1 to $0^{\circ} \mathrm{C}$ ) would provide half to a quarter of this heat. If the coastal circulation is a gyre, then the frictional layer would transport the water only to the center of the shelf (center of the gyre).

This bottom frictional intrusion process would act uniformly along the shelf break which is contrary to observations - warm water intrusions occur at fixed locations that are tied to bathymetric features (Klinck et al., 2004; Dinniman and Klinck, 2004). Also, warm intrusions are observed in places where the alongshore flow would give rise to offshore transport in the bottom frictional layer, e.g., Ross Sea (Dinniman et al., 2007; Orsi and Wiederwohl, 2009).

\subsection{Flow inertia and bathymetry}

Flow along a shelf break with a corrugated bathymetry can produce net onshore intrusion of water (Dinniman et al., 2003; Dinniman and Klinck, 2004). The basic mechanism is due to the inertia of the flow in the presence of bathymetry that curves offshore in front of alongshore flow; inertia pushes water onto the shelf. For the water to intrude over the shelf proper, there must be onshore flow on the shelf that will pull the recently upwelled water across the shelf. Because of this two-step process, not all locations with offshore curving isobaths are sites of cross-shelf exchange.

While this process has been shown to be active in models of both the Ross Sea (Dinniman et al., 2003) and the WAP (Dinniman and Klinck, 2004), the detailed dependence on flow speed, bathymetry and temporal variations has not been analyzed. The speed of the ACC is known to be variable (Hughes et al., 2003; Meredith et al., 2004). We do not know if there is a threshold speed below which this process is ineffective or if intrusions occur only during accelerations of the ACC.

\subsection{ACC density variation due to thermal wind}

The ACC is a geostrophically balanced flow with vertical shear that, by the thermal wind relation (1) below, requires that the density increase to the south, thereby supporting the continual rise of isopycnals towards the south. Imbedded within this general rise are sharper density slopes at locations of the three important frontal jets (Orsi et al., 1995).

The integrated transport of the ACC is known to be time variable (Cunningham et al., 2003; Hughes et al., 2003; Meredith et al., 2004; Meredith and Hughes, 2005). Part of the speed change could be associated with changes in the vertical shear that gives rise to variations in the depth of isopycnals along the Antarctic coast. Hydrographic observations over the years do not find large differences in the depth of certain isopycnals (for instance, the $27.70 \sigma_{o}$ potential density - relative to the surface, $\mathrm{kg} \mathrm{m}^{3}$ - surface associated with $\mathrm{CDW})$. Nevertheless, it is possible that there is some vertical excursion of these isopycnals that would result in increased (or decreased) access of CDW to the shelf break.

The following simplified calculation puts a bound on the vertical excursion of $\mathrm{CDW}$ along the continent that is associated with variations of ACC speed. The focus of this calculation is in Drake Passage where there are a large number of measurements. This area also allows a clear separation of the ACC from the currents that are part of the adjacent 
Subtropical and Polar Gyres (Rintoul and Sokolov, 2001; Gladyshev et al., 2008).

Assuming hydrostatic, geostrophic flow, the vertical shear of the through-passage flow $(v)$ is proportional to the horizontal gradient of density,

$v_{z}=\frac{\partial v}{\partial z}=-\frac{g}{f \rho_{o}} \frac{\partial \rho}{\partial x}$,

where $g$ is the acceleration of gravity, $f$ is the local Coriolis parameter and $\rho_{o}$ is the reference density. The origin of the right-handed coordinate system is at the surface on the northern edge of Drake Passage with $x$ positive to the south, $y$ positive to the east and $z$ positive upward.

For simplicity, let neutral density in Drake Passage be a linear function of both depth and across-passage distance, or $\rho(x, z)=a+b x-c z$, where $b$ and $c$ are the average acrosspassage and vertical density gradients, respectively.

Given this density field, the vertical shear in the Passage is constant. The vertically integrated transport $(V)$ is then

$V=\int_{-H}^{0} v(z) d z=v_{b} H+\frac{1}{2} v_{z} H^{2}$,

where $v_{\mathrm{b}}$ is the bottom speed and the total transport through the passage is $T=V L$ where $L$ is the width of the Passage. In the calculations below, $L=725 \mathrm{~km}$ and $H=3.8 \mathrm{~km}$.

We want to estimate the elevation of density surfaces along the southern side of the passage in response to changes in baroclinic transport. The various relations above can be used to specify the total transport as

$T=L H\left(v_{b}+\frac{H}{2} \frac{g}{|f| \rho_{o}} \frac{\partial \rho}{\partial x}\right)$

This relationship can be solved for the across-passage density gradient $(b)$. The depth of an isopycnal is obtained from the density equation as

$\hat{z}=(a+b x-\hat{\rho}) / c$

where $\hat{\rho}$ is the target density to track and $\hat{z}$ is its depth as a function of distance $(x)$ across the Passage.

The vertical density gradient for Drake Passage is estimated from neutral density along WOCE line S1 (Orsi and Whitworth, 2005, p. 2) as $0.8 \mathrm{~kg} \mathrm{~m}^{-3}$ over $3.8 \mathrm{~km}$ depth. The horizontal density gradient is obtained from the estimated baroclinic transport of $107.3 \pm 10.4 \mathrm{~Sv}$ (Cunningham et al., 2003). The elevation of CDW (density of 27.7 ) along the southern side of the Passage is known to be about $500 \mathrm{~m}$, the depth of the shelf break.

The purpose of this analysis is to estimate the depth change of CDW along the southern side of Drake Passage due to changes in ACC baroclinic transport. If we combine the equations above, assume that the average vertical density gradient does not change with transport and assume, without much observational support, that transport changes do not affect the depth of the isopycnal on the north side of the ACC, we can obtain an expression for the change in the south side depth $(\Delta \hat{z})$ as a function of the change in transport $(\Delta T)$ :

$\Delta \hat{z}=\frac{2|f| \rho_{o}}{H^{2} g c} \Delta T$

The estimated $10 \%$ variation in the baroclinic transport (Cunningham et al., 2003) produces about $100 \mathrm{~m}$ vertical excursion of the isopycnal associated with CDW. Lifting CDW to a depth of $200 \mathrm{~m}$ would require the baroclinic transport to increase to about $140 \mathrm{~Sv}$ (about $40 \%$ increase) which is a large (but not impossible) change.

We note in passing that increasing the horizontal density gradient will increase the potential energy of the ACC providing additional energy for baroclinic instability (CushmanRoisin, 1994), which could counteract the lifting effect of the increased transport (Böning et al., 2008). Similarly, increases in ACC transport may result in latitudinal shifts of the current which could amplify or diminish the resulting vertical excursion of CDW along the Antarctic shelf break. These issues would require more detailed calculations to analyze.

\subsection{Flow dynamic instability}

ACC frontal jets are known to be baroclinically unstable (Inoue, 1985; Moore et al., 1997, 1999; Sprintall, 2003; Dong et al., 2006) and there are suggestions that the ACC is actually in an "eddy saturated" (Hogg et al., 2008) state where wind increases do not significantly change the transport but instead increase the eddy kinetic energy (Meredith and Hogg, 2006).

The Southern ACC Front is very near the continental shelf along the Bellingshausen Sea so flow meanders or eddies can affect flow at the shelf break and thereby influence intrusions. There are two possible processes at work. One possibility is that the frontal jet can become unstable at any location and produce a meander or eddy. Another possibility is that bottom topography, in the form of ridges at the base of the continental slope, perturbs the flow at certain places triggering a meander or eddy. This topographically induced meander can interact with the shelf break to create site-specific locations of intermittent intrusions. The intrusion site at the offshore end of Marguerite Trough on the west Antarctic Peninsula is one such circumstance (Klinck et al., 2004; Moffat et al., 2009).

\subsection{Atmospherically forced exchange}

Direct atmospheric forcing of cross shelf exchange is mainly due to surface wind stress, but buoyancy flux can also force circulation (due to cooling or sea ice formation) that might affect shelf break exchange.

Wind driven upwelling occurs through frictional export of water in the surface layer and onshore replacement of water at depth. Along the Antarctic coast, upwelling winds would be westerlies (or southwesterlies along the WAP). Average winds along the Amundsen/Bellingshausen coast are easterlies (Hurrell et al., 1998), although the strength of these 
winds changes seasonally due to the migration of the Polar Trough (a low pressure band typically along $60^{\circ}$ to $70^{\circ} \mathrm{S}$ ). Similarly, winds along the Peninsula are onshore or southward (Hurrell et al., 1998). Thus, average winds will not create wind driven upwelling as found in typical upwelling areas, such as the northern half of the west coast of North America. Furthermore, Antarctic shelves are around $500 \mathrm{~m}$ deep, which is rather far for Ekman suction to lift water. Finally, no ocean observations exist near the coast in this area showing strongly lifted density surfaces that would be consistent with classical coastal upwelling.

A model study of the Pine Island Bay area (Thoma et al., 2008) shows that stronger westerly wind is associated with increased intrusions. This could be associated with upwelling, but it could also be associated with acceleration of the ACC along the shelf break creating stronger flow topography interaction or increased topographically induced meanders. Similar processes occur along the WAP (Dinniman et al., 2010).

Dense water formation, whether due to heat loss to the atmosphere at the surface or to ice formation or both, increases the volume of sub-pycnocline water which requires a subsurface offshore volume flux somewhere along the shelf. Because of entrainment during convection, it is possible for water at mid-depth to be lowered requiring lateral replacement from the shelf break. Dense water on the shelf can drive a cyclonic circulation (similar to a cold-core eddy) that could bring water on the shelf in one location while exporting water at another location. If water moves across the shelf break near a trough, then near-bottom water will flow with shallow bathymetry to its left creating a cyclonic circulation around a deep area. These circulation patterns are strongly influenced by bottom topography so the location of dense water formation is critical. For example, coastal polynyas are associated with coastal orography (valleys or ridges) and can create dense water at specific locations.

\subsection{Ice shelf circulation}

A vertical-plane circulation under an ice shelf is driven by basal melt - the so called "ice pump" (Lewis and Perkins, 1986). The freezing point of seawater decreases with depth (pressure) so water at the surface freezing temperature is above the subsurface freezing temperature and can melt the base of an ice shelf. This effect is particularly enhanced if warm water (CDW) moves under ice shelves. Basal melting makes the water fresher and buoyant which causes it to rise along the bottom of the ice shelf. Eventually, this water will reach a compensation density and will flow out from under the ice shelf - a mechanism that makes Ice Shelf Water (ISW). In some cases, such as the George VI Ice Shelf (Potter and Paren, 1985), the water becomes so buoyant that it rises to the surface and does not produce a mid-depth ISW plume but rather contributes to the fresh, cold water at the surface.
This buoyancy driven flow has the effect of pulling deeper water to the base of the ice shelf and exporting it at middepth (or higher). Analysis of Ross Sea model simulations (Hüsrevoğlu, 2008) shows that both High Salinity Shelf Water (HSSW) and modified CDW on the shelf are associated with this circulation. This forced circulation involves water in the mid- and inner-shelf, but the importance of this process in forcing flow across the distant shelf break is not known.

\section{Details of a regional ocean circulation model}

A more complete analysis of exchange processes requires consideration of the details of variable bottom topography, variable stratification, time and space varying forcing, and a number of other issues. These details are best considered in a numerical ocean circulation model.

Antarctic coastal numerical models need relatively small grid spacing for two major reasons. One reason is the need to represent ocean circulation with small spatial scales. The second reason is to represent atmospheric forcing which also can have relatively small spatial scales.

The first reason is due to the small radius of deformation (4-5 km) which sets the minimum radius of curvature for quasi-geostrophic flow and sets the diameter of mesoscale eddies. This dynamical scale also determines the minimum spatial scale for bathymetry. Thus, the maximum grid spacing for an Antarctic coastal model is a few to $10 \mathrm{~km}$. This grid size resolves most of the bottom features (banks and troughs) and would be "eddy-permitting". That is, the model would allow some flow meandering and would represent mesoscale eddies by a few (4 or 5) grid points.

The second reason is the need for fine scale atmospheric information. The major issue is proper representation of katabatic winds (Bromwich and Parish, 1998), which are drainage flows of dense air from the high interior of Antarctica. These winds either flow along the side of mountain ranges (such as the barrier winds along the Transantarctic Mountains or the Antarctic Peninsula) or collect in valleys which open to the coast (such as that in Terra Nova Bay in the southwestern Ross Sea). Because of the topographic constraint, they can be very strong, although relatively narrow and close to the coast. These winds are important in creating polynyas which are areas of open water during times when freezing should create an ice-covered ocean.

A further, less dramatic, reason for fine scale atmospheric information is the need to represent the effect of the various mountain ranges on the general atmospheric circulation. For example, the high mountains along the spine of the Antarctic Peninsula create winds within a few tens of $\mathrm{km}$ of the coast which are not well represented by the global atmospheric analysis models. The Antarctic Mesoscale Prediction System (AMPS) (Powers et al., 2003; Bromwich et al., 2005) uses a mesoscale meteorolgical model with grid spacing in different domains of 6 to $30 \mathrm{~km}$. These models 


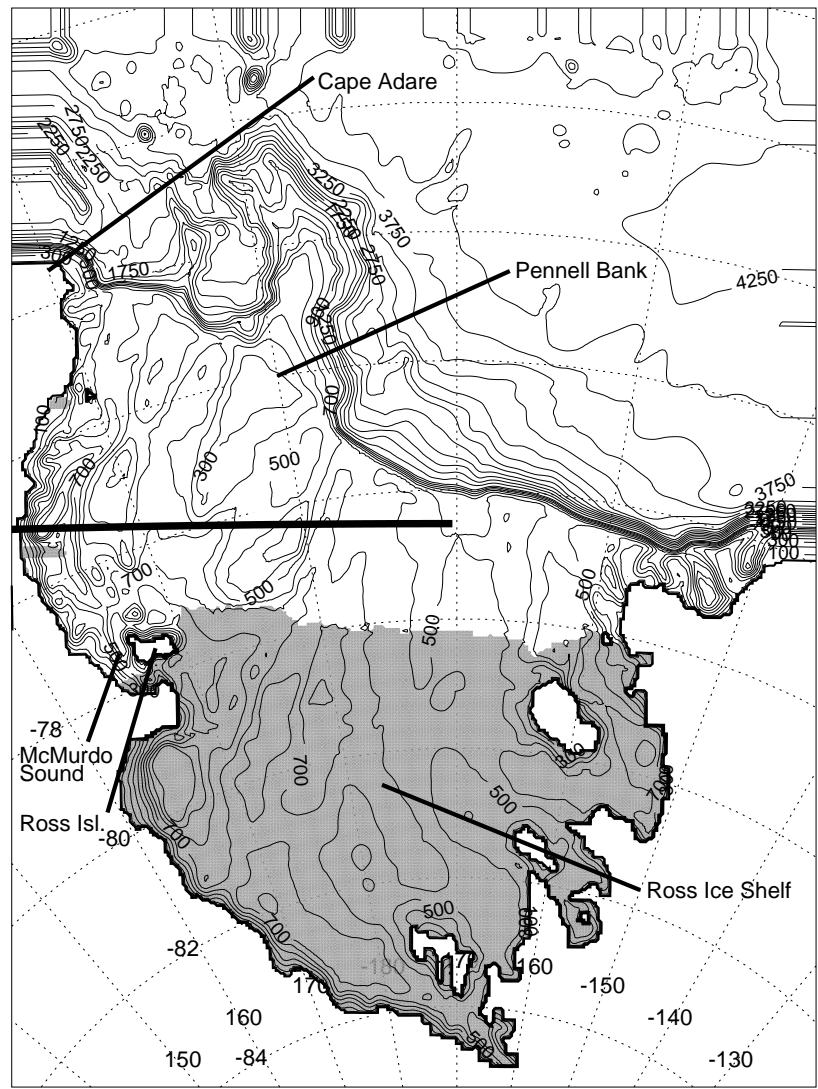

Fig. 1. Domain for Ross Sea model. The contour interval for the bathymetry is $100 \mathrm{~m}$ up to $1000 \mathrm{~m}$ depth and $250 \mathrm{~m}$ beyond. The shaded area is the part of the model covered by the Ross Ice Shelf. The horizontal line is the cross section for Fig. 2.

better represent the atmospheric conditions over the Antarctic coastal areas.

For all of these reasons, regional ocean circulation models along the Antarctic coast need to have grid spacing smaller than $10 \mathrm{~km}$. Adequate resolution of the structure of the flow in these regions may argue for grid spacings as small as $1 \mathrm{~km}$. Such small grid spacing would require bottom topography at the same scale, which exists in some, but not all, areas of the Antarctic continental shelf.

\subsection{ROMS model description}

The results from an ocean circulation model of the Ross Sea, based on the Regional Ocean Model System (ROMS) (Shchepetkin and McWilliams, 2005; Haidvogel et al., 2008), are used to illustrate high latitude exchange processes. ROMS is a 3-D primitive equation, finite difference model that uses a terrain following vertical coordinate system. This model is similar to that described in Dinniman et al. (2007), which includes the water filled cavity under the Ross Ice Shelf (RIS) and has sea ice that is imposed from observations rather than calculated from a sea-ice dynamic/thermodynamic model.

The model domain (Fig. 1) extends from well north $\left(67.5^{\circ} \mathrm{S}\right)$ of the continental shelf break southward to $85^{\circ} \mathrm{S}$, which includes almost all of the cavity beneath the RIS. The horizontal grid spacing is $5 \mathrm{~km}$ with 24 vertical levels whose thickness varies with the water column depth but are concentrated towards the top and bottom surfaces.

Two bathymetric surfaces must be defined for this model: the bottom of the water column and, where necessary, the draft below mean sea level of the ice shelf. Both of these were obtained from the BEDMAP gridded digital model of ice thickness and sub-glacial topography for Antarctica (Lythe et al., 2001), with additional data for the open shelf from a digitized version of an updated Ross Sea bathymetry (Davey, 2004).

Initial fields of temperature and salinity are obtained from the World Ocean Atlas 2001 (Boyer et al., 2002). Open boundaries for all runs are handled as in (Dinniman et al., 2007).

Vertical momentum and tracer mixing use the $\mathrm{K}$ profile parameterization (KPP) mixing scheme (Large et al., 1994) with the small changes for sea ice given in Dinniman et al. (2003). Daily winds were obtained from AMPS. The model is spun-up for six years using a repeatable cycle of daily winds over a two year (2000 and 2001) period and then is forced by daily winds covering the period 15 September 2001-15 September 2003.

\subsubsection{Sea ice and open water}

In place of a fully dynamic sea ice model, ice concentration from the Special Sensor Microwave Imager (SSM/I) is imposed. The model surface heat flux is calculated as a linear combination of heat flux through the ice cover and open water with the ratio determined by the ice concentration in that grid cell (Markus, 1999). Additional details on the surface fluxes are given in Dinniman et al. (2007).

\subsubsection{Ice shelf}

The thickness and extent of the ice shelf do not change for these simulations. Under the ice, the upper boundary of the model conforms to the ice shelf base. The hydrostatic pressure at the base of the ice shelf is computed by the integral over depth of the density of the water replaced by the ice. The details of this calculation are given in Dinniman et al. (2007).

The drag of the moving water against the bottom of the ice shelf is represented by a quadratic stress with a coefficient of $3.0 \times 10^{-3}$ (non-dimensional). A three equation model for the conservation of heat and salt is applied to a thin layer at the ice-water interface. The equations and parameter values are given in Dinniman et al. (2007) except that the heat and salt 
transfer coefficients are no longer constant but are functions of the friction velocity (Holland and Jenkins, 1999).

\subsection{Analysis methods}

There are a variety of ways to analyze numerical model results to determine exchange across the shelf break. The flux of any number of properties (volume, salt, heat, etc.) can be readily calculated across a plane defined by the shelf break. In highly variable flow, it is often necessary to either save the solution often (daily or more often), or to save time averages of terms in the budget equations to allow more accurate flux calculations.

In these experiments, we use water properties (temperature and salinity) to mark the rate and direction of exchange as well as to partition the exchange by water types. In the Ross Sea, we are interested in the onshore movement of CDW, which provides a source of heat and nutrients. We are also interested in the offshore transport of cold, salty water (HSSW) that is the source of dense bottom water.

The most identifiable feature of the onshore moving CDW is its relatively high temperature compared to water on the shelf. However, due to efficient vertical and horizontal heat exchange, this water rapidly loses its excess heat making it difficult to track. Instead, we use an artificial dye to track CDW on the shelf and to identify the processes by which its properties change. Specifically, we use a scalar which advects and diffuses in the same way as salt. This scalar is initially set to a value of 100 at offshelf locations (no dye on the shelf initially) which are occupied by CDW (defined by temperature $>0.0^{\circ} \mathrm{C}$ ). A second identifiable water mass is HSSW which is the cold and salty water formed in the polynyas of the southwestern Ross Sea. Salinity greater than 34.6 for water deeper than $200 \mathrm{~m}$ is the best indicator of this water.

\section{Results}

\subsection{Model comparison for salinity}

A zonal-vertical section of salinity (Fig. 2) across the Ross Sea gives a clear indication that various model processes are working correctly. Model results for summer (12 February) show high salinity at depth in the far west with decreasing salinity both to the east and to the surface. A shallow surface mixed layer exists in the west and deepens to about $50 \mathrm{~m}$ in the central and eastern areas. In the winter (30 September), parts of the western Ross Sea have mixed to the bottom, while the eastern Ross Sea maintains its stratification even under winter conditions. Results from a new high resolution climatology of the Ross Sea (Orsi and Wiederwohl, 2009) compare best with the summer results because most of the hydrographic observations are from the ice-free summer months.

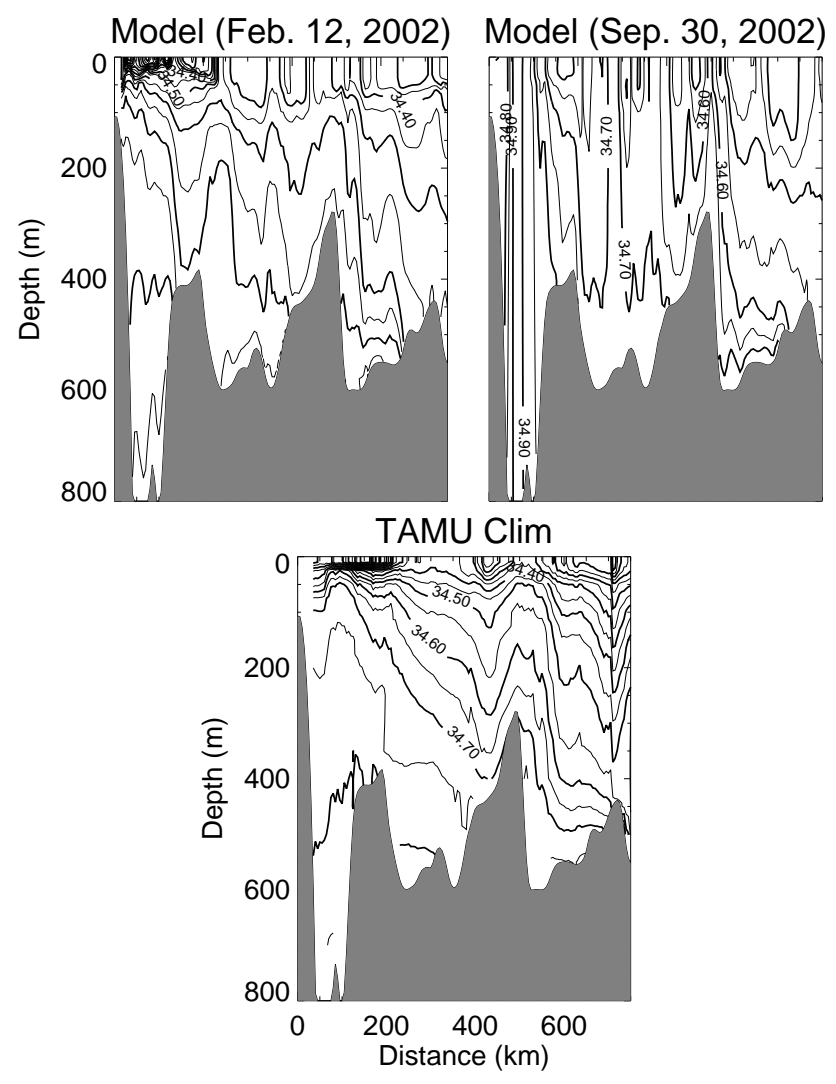

Fig. 2. Model salinity compared to climatological salinity from Orsi and Wiederwohl (2009). The upper two panels are the salinity section (see Fig. 1) from west to east across the Ross Sea during summer and winter. The lower panel is the climatological salinity from Orsi and Wiederwohl (2009).

The model salinity at $300 \mathrm{~m}$ depth (Fig. 3) shows the location of HSSW and the path of this water as it flows away from the formation region. The highest salinity is found near Terra Nova Bay; this water drains both northward and southward along the coast. The climatology (Fig. 4) has a bit more structure, but the general pattern of salinity shows that the model is acting realistically on the shelf.

The lowest salinity water at $300 \mathrm{~m}$ (Figs. 3 and 4) occurs in the eastern Ross Sea near the edge of the Ross Ice Shelf (RIS). This lower salinity in the eastern Ross Sea is due to reduced ice production (due to persistent sea ice cover and no polynyas), import of fresher water from the east and melting of the RIS (Jacobs et al., 2002).

\subsection{Ocean exchange indicated by temperature}

Annual mean temperature at $300 \mathrm{~m}$ (Fig. 5) provides a smoothed image of the location and path of CDW water intrusion onto the shelf from the ocean. Specifically, water warmer than $-1.0 \mathrm{C}$ must have recently crossed the shelf break. These intrusions occur in certain places - one large area in the eastern Ross Sea $\left(180^{\circ} \mathrm{E}\right.$ to $\left.170^{\circ} \mathrm{E}\right)$ as well as 

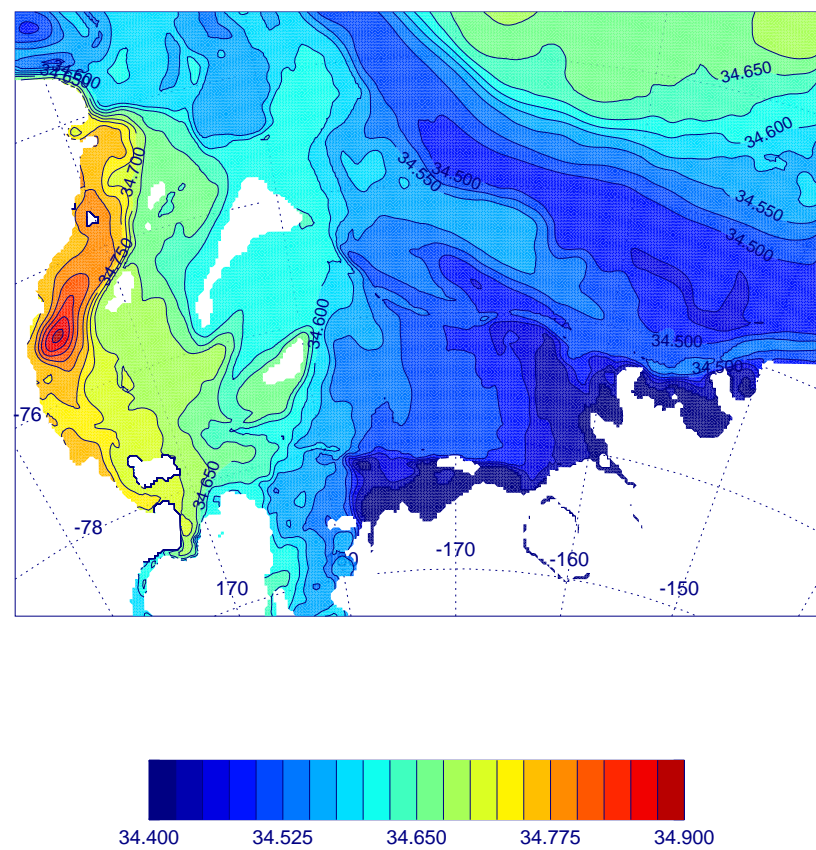

Fig. 3. Annual average salinity at $300 \mathrm{~m}$ from the simulation model. White areas in the figure are either land or areas that are shallower than $300 \mathrm{~m}$.
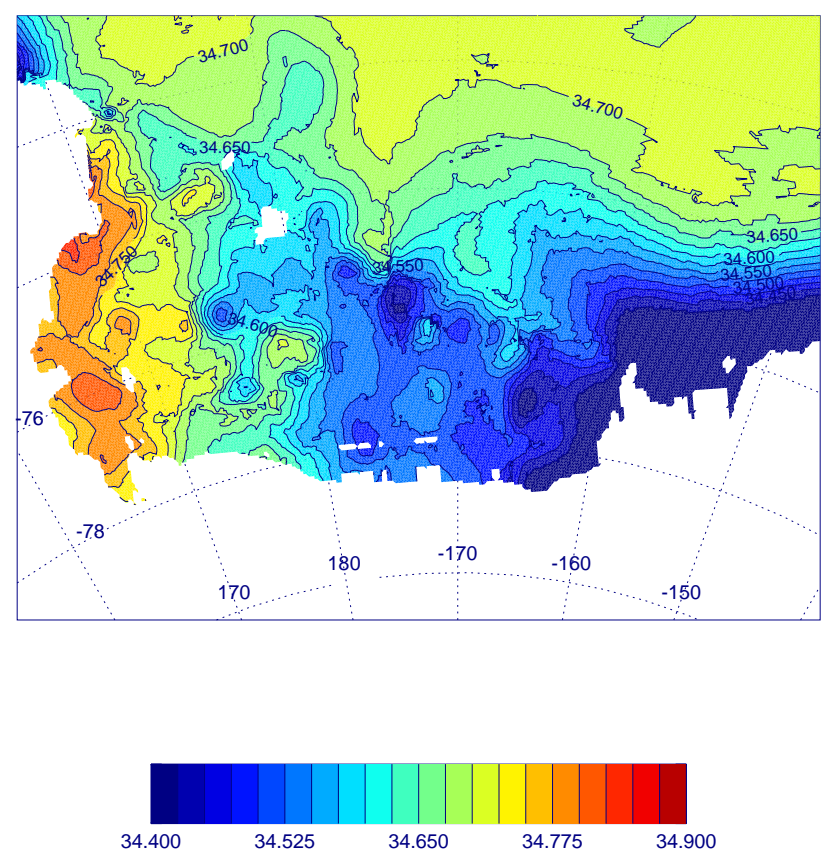

Fig. 4. Climatological salinity at $300 \mathrm{~m}$ from Orsi and Wiederwohl (2009). White areas in the figure are either land, areas that are shallower than $300 \mathrm{~m}$ or areas with no data (i.e. beneath Ross Ice Shelf).
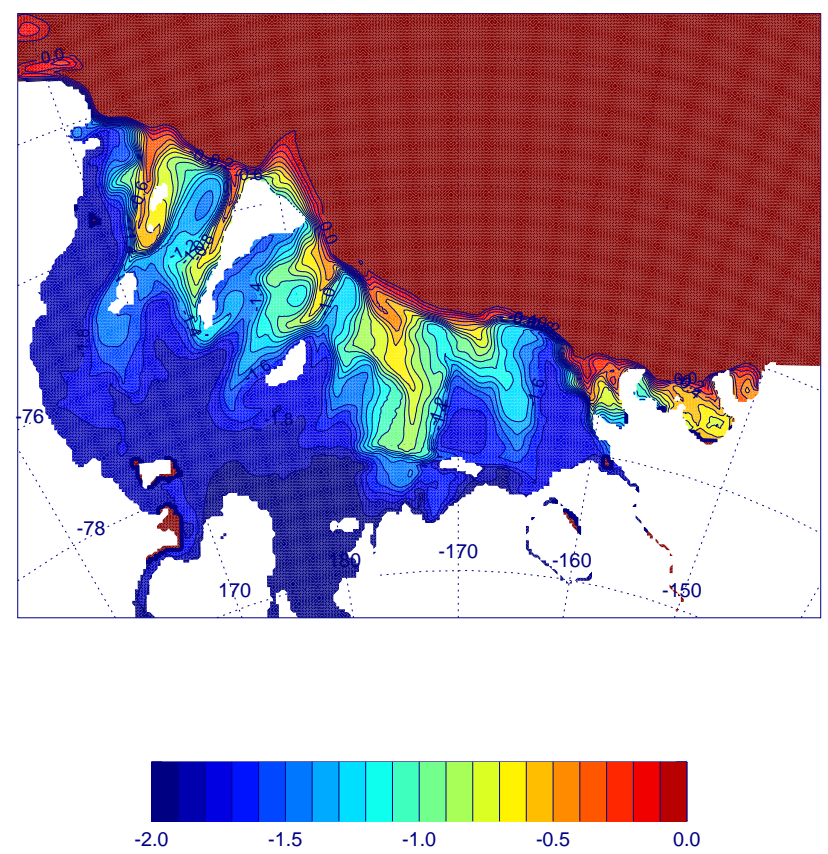

Fig. 5. Annual mean temperature at $300 \mathrm{~m}$ from the simulation model. White areas in the figure are either land or areas that are shallower than $300 \mathrm{~m}$.

several narrow, persistent streams entering along the western side of several banks (e.g. Pennell Bank at $175^{\circ} \mathrm{W}$ ). These locations of onshore movement of CDW are consistent with observed locations (Orsi and Wiederwohl, 2009) and demonstrate that bottom topography controls these locations.

\subsection{Ocean exchange indicated by theoretical dye}

The CDW dye streams onto the shelf from early times in the simulation. After $412 \mathrm{~d}$ of simulation (Fig. 6), the dye indicates locations along the western part of the shelf break (near Pennell Bank and westward) where active exchange occurs. The highest dye concentrations are along the western sides of the various banks in the western Ross Sea, consistent with the temperature (Fig. 5).

The near surface dye concentration (Fig. 7) shows that CDW is crossing the pycnocline and reaching the surface. This is an indication that there is vertical exchange across the pycnocline. Analysis of the advection/diffusion equation for dye reveals two processes moving dye to the surface over the shelf: local, cross-pycnocline, vertical diffusive flux and onshore transport of surface dye that moved to the surface near the shelf break. 

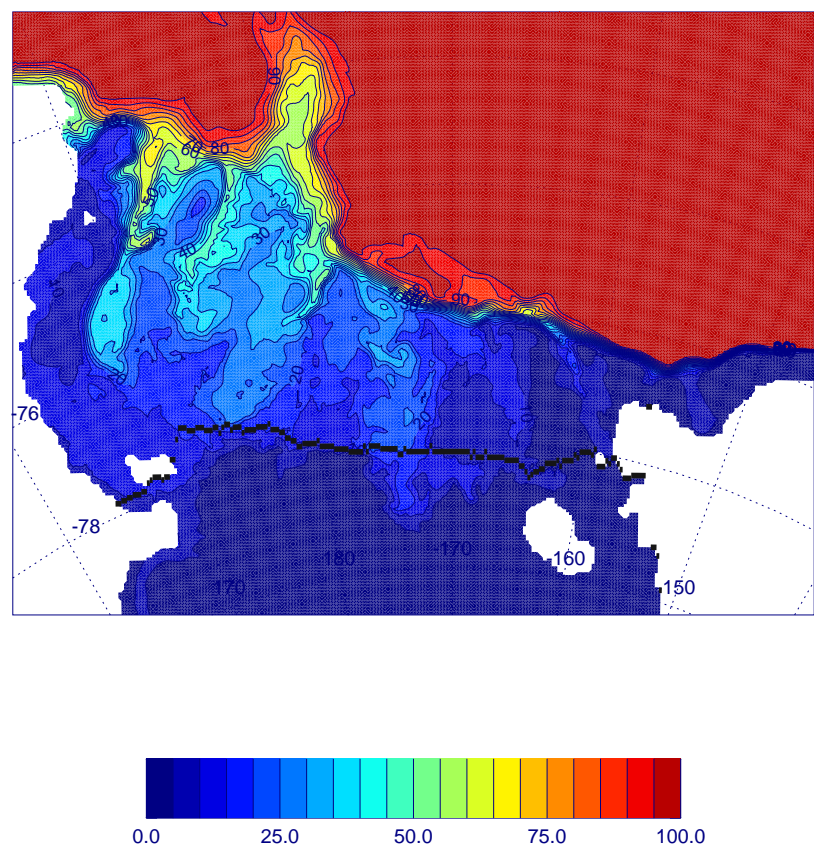

Fig. 6. CDW dye on model level 12 (mid-depth) for 1 November 2002. Dye values of 100 are undiluted CDW. The black line represents the position of the Ross Ice Shelf Front.

\section{Discussion}

\subsection{Topographic effect on intrusion locations}

Circulation at high southern latitudes responds to small scale topography due to the small stratification and small radius of deformation. In addition, the strong flow at the shelf break is a critical element of the processes which move water from the oceanic side of the shelf break to the shelf side. Finally, the speed of the flow at the shelf break may change due to external forcing (either local winds or global averaged winds) which can affect the time variability of the onshore intrusions. For these reasons, it is important to design a numerical grid with small grid spacing and to impose realistic bathymetry.

\subsection{Effects of polynyas}

Polynyas are an important component of the dynamics and thermodynamics of high latitude ocean systems. In the Antarctic, they are important for creation of dense waters in some areas. The main forcing mechanism for many polynyas is an offshore wind stress to clear the coastal area of newly created ice. Polynyas are mostly associated with land orography which channels winds across certain parts of the coast. Polynya locations are thus fixed in space.

Due to the strong exchange with the atmosphere, polynyas are also locations of strong vertical convection which has the effect of injecting surface waters deep into the ocean, often
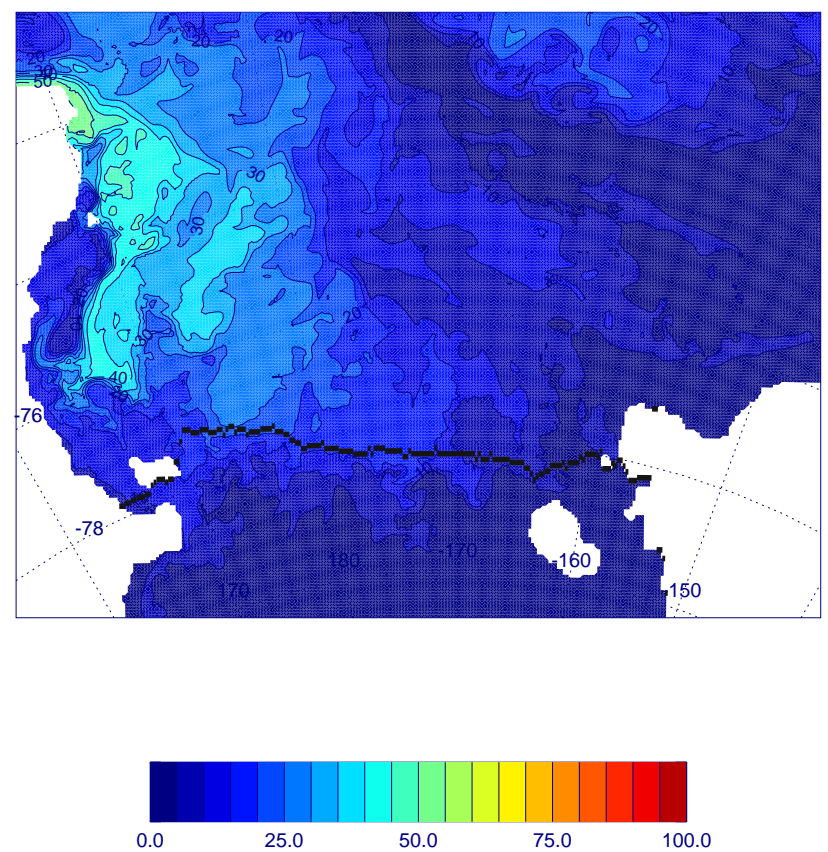

Fig. 7. CDW dye on the surface for 1 November 2002. Dye values of 100 are undiluted CDW. The black line represents the position of the Ross Ice Shelf Front.

to the bottom. This vertical convection involves entrainment which drags other waters deeper. Processes associated with polynyas are an efficient means to move surface properties to the bottom on the shelf, as well as, into the abyssal ocean. Finally, it should be noted that polynyas tend to be small in area but can have global consequences due to the dense water that they produce.

\subsection{Climate change speculations}

We are all aware of the changes now occuring in various parts of the atmosphere and ocean. These changes are modifying the character of ocean water masses and their circulation. We would like to offer some speculations on the possible effects of these changes.

Under different surface forcing, the ACC is thought to change its location (Fyfe and Saenko, 2005, 2006). If these lateral shifts occur, then the water being presented to the shelf break around the Antarctic will change. If different types of water move onto the shelf break then there can be radical changes in the heat and salt fluxes as well as changes to the biological systems that depend on nutrients provided by these exchanges. In addition to changing the character of the water at the shelf break, increased surface forcing can give rise to an increased number of mesoscale eddies (Hogg et al., 2008) which has the potential to affect the volume of water crossing the shelf break. These questions invoke dynamical subtleties which are not easily analyzed analytically; detailed 
numerical studies will be needed to untangle the important effects of changes in surface forcing of the ACC.

Varying speed of the ACC, without shifts in location, can lead to a different type of water being available for exchange at the shelf break. These changes in the vertical structure of the ACC influence the location of surfacing of various deep water masses which can have locally important effects on coastal systems. These differences can affect the atmosphere creating a feedback loop to modify these exchanges.

One effect of increased exchange of water across the shelf break is warmer subsurface water on the shelf. Changes in the winds may also lead to more vertical mixing and loss of this heat to the atmosphere. However, if this water moves under ice shelves quickly enough to retain most of its excess heat, then it can increase the melt rate of the bottom of the ice shelves. A number of research programs are looking at these exchange processes both with observations and with theoretical calculations. Removal of ice shelves can fundamentally alter the water structure and circulation of various coastal areas. Changing the floating end of glacial ice can impact the rate of movement of the whole ice sheet. In addition, the newly ice-free ocean areas can exchange heat and moisture with the atmosphere which can influence its circulation. Whether these changes will amplify or diminish the cross shelf exchange is at present unknown.

The changing strength of katabatic winds can have an important effect on the size, location and even existence of polynyas around the Antarctic continent. Katabatic winds respond to changes in the atmosphere since they are due to dense dry air created on the polar plateau which drains to the coast by various paths controlled by orography. Changes in the density of the air on the plateau will change the pressure gradients driving these flows. Over the last 20 to 200 years, there has been no persistent temperature change at South Pole although some warming is occuring over West Antarctica (Mayewski et al., 2009). Given the importance of polynyas in creating dense water, these changes to katabatic winds may have far reaching effects on the strength of the ocean overturning circulation. Latent heat release over the ocean is likely to have an influence in the lower atmosphere over the polynya but it is unknown if this will feedback on the dense air created over the Antarctic Plateau.

\section{Conclusions}

Exchange of water across the Antarctic shelf break is important because of its effects on circulation and biology. In particular, conversion of water masses on these shelves is part of the global overturning circulation. Heat from oceanic water can melt glacial ice thereby influencing global sea level.

A variety of physical mechanisms are described which can influence onshore flux of warm oceanic water. Flow instability and flow-topography interaction are shown to be important for exchange. Wind driven and bottom Ekman layer exchange are argued not to be important.

A numerical model for the Ross Sea continental shelf is used for more detailed evaluation of cross-shelf exchange. Analysis of salt and temperture distributions show persistent exchange at certain locations controlled by bottom topography. An artificial dye is use to mark CDW to better analyze the influence of the oceanic water, even in diluted amounts. Model results show a vigorous onshore flux of oceanic water across the shelf break both at depth and at the surface as well as creation of dense HSSW by coastal polynyas in the western Ross Sea. Salinity distributions indicate movement of HSSW both northward to the shelf break and southward under the Ross Ice Shelf.

As part of this study, it was determined that for an ocean circulation model to simulate processes at high southern latitudes, it needs to have high spatial resolution, realistic geometry and bathymetry. Grid spacing must be smaller than the first baroclinic radius deformation (a few $\mathrm{km}$ ). Because of flow-topography interactions, bathymetry needs to be well represented at these same small scales. Atmospheric forcing conditions also need to be given at a similar small spatial resolution (a few $\mathrm{km}$ ) in order to represent orographically controlled winds (coastal jets) and katabatic winds. Furthermore, daily, if not more frequent, surface fluxes must be imposed for a realistic surface mixed layer. Sea ice and ice shelves both isolate the ocean from the atmosphere, and modify the character of water masses by freezing and melting.

Acknowledgements. The BEDMAP data was provided courtesy of the BEDMAP consortium (http://www.antarctica.ac.uk/ bas_research/data/access/bedmap/). The AMPS data was provided by John Cassano and AMPS is supported by US National Science Foundation support to NCAR, Ohio State University and the University of Colorado. Computer facilities and support were provided by the Commonwealth Center for Coastal Physical Oceanography. This work was supported by the US National Science Foundation grant OPP-03-37247.

Edited by: J. A. Johnson

\section{References}

Böning, C. W., Dispert, A., Visbeck, M., Rintoul, S. R., and Schwarzkopf, F. U.: The response of the Antarctic Circumpolar Current to recent climate change, Nat. Geosci., 1, 864-869, 2008.

Boyer, T. P., Stephens, C., Antonov, J. I., Conkright, M. E., Locarnini, R. A., O’Brien, T. D., and Garcia, H. E.: World Ocean Atlas 2001, Volume 2, edited by: Salinity, S. and Levitus, S., NOAA Atlas NESDIS 50, US Government Printing Office, Washington, DC, 165 pp., CD-ROMs, 2002.

Bromwich, D. H. and Parish, T. R.: Meteorology of the Antarctic. In Meteorology of the Southern Hemisphere, edited by: Karoly, D. J. and Vincent, D. G., Meteorological Monographs, Am. Meteorol. Soc., Boston, 27(49), 175-200, 1998. 
Bromwich, D. H., Monaghan, A. J., Manning, K. W., and Powers, J. G.: Real-time forecasting for the Antarctic, An evaluation of the Antarctic Mesoscale Prediction System (AMPS), Mon. Weather Rev., 133, 579-603, 2005.

Cunningham, S. A., Alderson, S. G., King, B. A., and Brandon, M. A.: Transport and variability of the Antarctic Circumpolar Current in Drake Passage, J. Geophys. Res., 108, 8084, doi:10.1029/2001JC001147, 2003.

Cushman-Roisin, B.: Introduction to Geophysical Fluid Dynamics, Prentice-Hall, Upper Saddle River, NJ, 320 pp., 1994.

Davey, F. J.: Ross Sea Bathymetry, 1:2000 000, version 1.0, Institute of Geological \& Nuclear Sciences geophysical map 16, Institute of Geological \& Nuclear Sciences, Limited, Lower Hutt, New Zealand, 2004.

Dinniman, M. S., Klinck, J. M., and Smith, Jr., W. O.: Cross-shelf exchange in a model of the Ross Sea circulation and biogeochemistry, Deep-Sea Res. Pt. II, 50, 3103-3120, 2003.

Dinniman, M. S. and Klinck, J. M.: A model study of circulation and cross-shelf exchange in the west Antarctic Peninsula continental shelf, Deep-Sea Res. Pt. II, 51, 2003-2022, 2004.

Dinniman, M. S., Klinck, J. M., and Smith, Jr., W. O.: The influence of sea ice cover and icebergs on circulation and water mass formation in a numerical circulation model of the Ross Sea, Antarctica, J. Geophys. Res., 112(C11), C11013, doi:10.1029/2006JC004036, 2007.

Dinniman, M. S., Klinck, J. M., and Smith, Jr., W. O.: A model study of Circumpolar Deep Water on the West Antarctic Peninsula and Ross Sea continental shelves, Deep Sea Res. Pt. II, submitted, 2010.

Dong, S., Sprintall, J., and Gille, S. T.: Location of the Polar front from AMSR-E satellite sea surface temperature measurements, J. Phys. Oceanogr., 36, 2075-2089, 2006.

Erofeeva, S.Y., Egbert, G. D., and Padman, L.: Assimilation of shipmounted ADCP data for barotropic tides: Application to the Ross Sea, J. Atmos. Ocean. Tech., 22(6), 721-734, 2005.

Fyfe, J. C. and Saenko, O. A.: Human-induced changes in the Antarctic Circumpolar Current, J. Climate, 18(15), 3068-3073, 2005.

Fyfe, J. C. and Saenko, O. A.: Simulated changes in the extratropical Southern Hemisphere winds and currents, Geophys. Res. Lett., 33, L06701, doi:10.1029/2005GL025332, 2006.

Gladyshev, S., Arhan, M., Solov, A., and Speich, S.: A hydrographic section from South Africa to the southern limit of the Antarctic Circumpolar Current at the Greenwich meridian, DeepSea Res. Pt. I, 55, 1284-1303, doi:10.1016/j.dsr.2008.05.009, 2008.

Gouretski, V.: The large-scale thermohaline structure of the Ross Gyre, in: Oceanography of the Ross Sea Antarctica, edited by: Spezie, G. and Manzella, G. M. R., Springer-Verlag, Milan, 77$102,1999$.

Gordon, A. L., Orsi, A. H., Muench, R., Huber, B. A., Zambianchi, E., and Visbeck, M.: Western Ross Sea continteal slope gravity currents, Deep-Sea Res. Pt. II, 56, 796-817, doi:10.1016/j.dsr2.2008.10.037, 2009.

Haidvogel, D. B., Arango, H., Budgell, W. P., Cornuelle, B. D., Curchitser, E., Di Lorenzo, E., Fennel, K., Geyer, W. R., Hermann, A. M., Lanerolle, L., Levin, J., McWilliams, J. C., Miller, A. J., Moore, A. M., Powell, T. M., Shchepetkin, A. F., Sherwood, C. R., Signell, R. P., Warner, J. C., and Wilkin, J.: Ocean forecasting in terrain-following coordinates: formulation and skill assessment of the Regional Ocean Modeling System, J. Comp. Physiol., 227, 3595-3624, 2008.

Hofmann, E. E. and Klinck, J. M.: Hydrography and circulation of the Antarctic continental shelf, in: $150 \mathrm{E}$ to the Greenwich Meridian, The Sea, The Global Coastal Ocean, edited by: Robinson, A. R. and Brink, K. H., Regional Studies and Synthesis, 11, 997-1042, 1998.

Hofmann, E. E. and Hüsrevoğlu, Y. S.: A circumpolar modeling study of habitat control of Antarctic krill (Euphausia superba) reproductive success., Deep-Sea Res. Pt. II, 50, 3121-3142, 2003.

Hogg, A. C., Meredith, M. P., Blundell, J. R., and Wilson, C.: Eddy heat flux in the Southern Ocean: Response to Variable Wind Forcing, J. Climate, 21, 608-620, 2008.

Holland, D. M. and Jenkins, A.: Modelling thermodynamic iceocean interactions at the base of an ice shelf, J. Phys. Oceanogr., 29, 1787-1800, 1999.

Hughes, C. W., Woodworth, P. L., Meredith, M. P., Stepanov, V., Whitworth, T., and Pyne, A. R.: Coherence of Antarctic sea levels, Southern Hemisphere Annular Mode and flow through Drake Passage, Geophys. Res. Lett., 30, 1464, doi:10.1029/2003GL017240, 2003.

Hurrell, J. W., van Loon, H., and Shea, D. J.: The mean state of the troposphere, in: Meteorology of the Southern Hemisphere, edited by: Karoly, D. J. and Vincent, D. G., Am. Meteorol. Soc., Meteor. Mon., 27(49), 1-46, 1998.

Hüsrevoğlu, Y. S.: Modeling the seasonal sea ice cycle in the Ross Sea, Antarctica, PhD Thesis, Old Dominion University, 2008.

Inoue, M.: Modal decomposition of the low-frequency currents and baroclinic instability at Drake Passage, J. Phys. Oceanogr., 15, 1157-1181, 1985.

Ivanov, V., Shapiro, G., Huthnance, J., Aleynik, D., and Golovin, P.: Cascades of dense water around the world ocean, Prog. Oceanogr., 60, 47-98, 2004.

Jacobs, S. S., Giulivi, C. F., and Mele, P. A.: Freshening of the Ross Sea during the late 20th century, Science, 297, 386-389, 2002.

Klinck, J. M., Hofmann, E. E., Beardsley, R. C., Salihoglu, B., and Howard, S.: Water-mass properties and circulation on the west Antarctic Peninsula continental shelf in austral fall and winter 2001, Deep-Sea Res. Pt. II, 51, 1925-1946, 2004.

Large, W. G., McWilliams, J. C., and Doney, S. C.: Oceanic vertical mixing: a review and model with a nonlocal boundary layer parameterization, Rev. Geophys., 32, 363-403, 1994.

Legg, S., Briegleb, B., Chang, Y., Chassignet, E. P., Danabasoglu, G., Ezer, T., Gordon, A. L., Griffies, S., Hallberg, R., Jackson, L., Large, W., Özgökmen, T. M., Peters, H., Price, J., Riemenschneider, U., Wu, W., Xu, X., and Yang, J.: Improving oceanic overflow representation in climate models, the Gravity Current Entrainment Climate Process Team, B. Am. Meteorol. Soc., 90, 657-690, doi:10.1175/2008BAMS2667.1, 2009.

Lewis, E. L. and Perkins, R. G.: Ice pumps and their rates, J. Geophys. Res., 91, 11756-11762, 1986.

Lythe, M. B., Vaughan, D. G., and the BEDMAP Consortium: BEDMAP: A new ice thickness and subglacial topographic model of Antarctica, J. Geophys. Res., 106, 11335-11352, doi:10.1029/2000JB900449, 2001.

Makinson, K.: Modeling tidal current profiles and vertical mixing beneath Filchner-Ronne Ice Shelf, Antarctica, J. Phys. Oceanogr., 32, 202-215, 2002. 
Markus, T.: Results from an ECMWF-SSM/I forced mixed layer model of the Southern Ocean, J. Geophys. Res., 104(C7), 1560315620, 1999.

Mayewski, P. A., Meredith, M. P., Summerhayes, C. P., Turner, J., Worby, A., Barrett, P. J., Casassa, G., Bertler, N. A. N., Bracegirdle, T., Naveira Garabato, A. C., Bromwich, D., Campbell, H., Hamilton, G. S., Lyons, W. B., Maasch, K. A., Aoki, S., Xiao, C., and van Ommen, T.: State of the Antarctic and Southern ocean climate system, Rev. Geophys., 47, RG1003, doi:10.1029/2007RG000231, 2009.

Meredith, M. P., Woodworth, P. L., Hughes, C. W., and Stepanov, V.: Changes in the ocean transport through Drake Passage during the 1980s and 1990s, forced by changes in the Southern Annular Mode, Geophys. Res. Lett., 31, L21305, doi:10.1029/2004GL021169, 2004.

Meredith, M. P. and Hughes, C. W.: On the sampling timescale required to reliably monitor interannual variability in the Antarctic circumpolar transport, Geophys. Res. Lett., 32, L03609, doi:10.1029/2004GL022086, 2005.

Meredith, M. P. and Hogg, A. M.: Circumpolar response of Southern Ocean eddy activity to a change in Southern Annular Mode, Geophys. Res. Lett., 33, L16608, doi:10.1029/2006GL026499, 2006.

Moffat, C., Owens, B., and Beardsley, R. C.: On the characteristics of Circumpolar Deep Water intrusions to the west Antarctic Peninsula Continental Shelf, J. Geophys. Res., 114, C05017, doi:10.1029/2008JC004955, 2009.

Moore, J. K., Abbott, M. R., and Richman, J. G.: Variability in the location of the Antarctic Polar Front (90-20/,W) from satellite sea surface temperature data, J. Geophys. Res., 102, 27825 27833, 1997.

Moore, J. K., Abbott, M. R., and Richman, J. G.: Location and dynamics of the Antarctic Polar Front from satellite sea surface temperature data, J. Geophys. Res., 104, 3059-3073, 1999.

Orsi, A. H., Whitworth III, T., Nowlin, Jr., W. D.: On the meridional extent and fronts of the Antarctic Circumpolar Current, Deep-Sea Res. Pt. I, 42, 641-673, 1995.

Orsi, A. H. and Whitworth III, T.: Hydrographic Atlas of the World Ocean Circulation Experiment (WOCE), Volume 1: Southern Ocean, edited by: Sparrow, M., Chapman, P., and Gould, J., International WOCE Project Office, Southhampton, UK, 2005.
Orsi, A. H. and Wiederwohl, C. L.: A recount of Ross Sea waters, Deep-Sea Res. Pt. II, 56, 778-795, doi:10.1016/j.dsr2.2008.10.033, 2009.

Padman, L., Fricker, H. A., Coleman, R., Howard, S., and Erofeeva, S.: A new tidal model for the Antarctic ice shelves and seas, Ann. Glaciol., 34, 247-254, 2002.

Padman, L., Howard, S., Orsi, A. H., and Muench, R. D.: Tides of the northwestern Ross Sea and their impact on dense outflows of Antarctic Bottom Water, Deep-Sea Res. Pt. II, 56, 818-834, doi:10.1016/j.dsr2.2008.10.026, 2009.

Potter, J. R. and Paren, J. G.: Interaction between ice shelf and ocean in George VI Sound, Antarctica, in: Oceanology of the Antarctic Continental Shelf, edited by: Jacobs, S. S., AGU Antarct. Res. Ser., 43, 35-58, 1985.

Powers, J. G., Monaghan, A. J., Cayette, A. M., Bromwich, D. H., Kuo, Y.-H., and Manning, K. W.: Real-time mesoscale modeling over Antarctica: The Antarctic Mesoscale Prediction System (AMPS), B. Am. Meteorol. Soc., 84, 1533-1545, 2003.

Rintoul, S. R., Hughes, C. W., and Olbers, D.: The Antarctic Circumpolar Current System, in: Ocean Circulation and Climate, edited by: Seidler, G., Church, J., and Gould, J., Academic Press, 271-302, 2001.

Rintoul, S. R. and Sokolov, S.: Baroclinic transport variability of the Antarctic Circumpolar Current south of Australia (WOCE repeat section SR3), J. Geophys. Res., 106(C2), 2815-2832, 2001.

Shchepetkin, A. F. and McWilliams, J. C.: The regional oceanic modeling system (ROMS): a split-explicit, free-surface, topography following coordinate ocean model, Ocean Model., 9, 347440, 2005.

Sprintall, J.: Seasonal to interannual upper-ocean variability in the Drake Passage, J. Mar. Res., 61, 27-57, 2003.

Stover, C. L.: A new account of Ross Sea waters: Characteristics, volumetrics and variability, M. S. thesis, Texas A\&M Univ, College Station, Texas, 100 pp., 2006.

ten Brink, U. S. and Cooper, A. K.: Modeling the bathymetry of the Antarctic continental shelf, in: Recent Progress in Antarctic Earth Science, edited by: Yoshida, Y., Kiminuma, K., and Kiraishi, K., Terra Scientific Publishing Co., 763-771, 1992.

Thoma, M., Jenkins, A., Holland, D., and Jacobs, S.: Modelling Circumpolar Deep Water intrusions on the Amundsen Sea continental shelf, Antarctica, Geophys. Res. Lett., 35, L18602, doi:10.1029/2008GL034939, 2008. 